\title{
Thermo-activated persulfate oxidation system for tetracycline antibiotics degradation in aqueous solution
}

\author{
Yuefei Ji, Yuanyuan Shi, Wei Dong, Xin Wen, Mengdi Jiang, Junhe Lu* \\ 210095, China \\ * Corresponding author. Tel.: +86 25 84395164; fax: +86 2584395164. \\ E-mail addresses: yuefeiji@njau.edu.cn (Y. Ji); jhlu@njau.edu.cn (J. Lu).
}

College of Resources and Environmental Science, Nanjing Agricultural University, Nanjing

\begin{abstract}
Tetracyclines (TCs), including tetracycline (TTC), oxytetracycline (OTC), and chlorotetracycline (CTC), are frequently detected in natural waters, soils, and sediments, which raised great concerns about the proliferation of antibiotic resistant genes. This study investigated the degradation of TCs by sulfate radical produced by thermo-activated persulfate in aqueous solution. Increasing the temperature significantly enhanced the degradation of TTC, and the relationship between pseudo-first-order rate constant $\left(k_{\mathrm{obs}}\right)$ and temperature obeyed Arrhenius equation. The degradation of TTC showed $\mathrm{pH}$ dependency, and $k_{\mathrm{obs}}$ increased markedly with increasing $\mathrm{pH}$. Seven intermediate products of TTC were temporarily identified by solid phase extraction and liquid chromatography-tandem mass spectrometry (SPE-LC-MS/MS). The transformation pathways of TTC included $N$-demethylation, hydroxylation-oxidation and dehydration. Detailed mechanisms for sulfate radical-induced $N$-demethylation and hydroxylation-oxidation were proposed. The degradation of the three TCs followed the order of OTC $>$ CTC $>$ TTC, highlighting the structure-specific reactivity. Interestingly, TTC was degraded extremely fast in artificial surface water (ASW), implying sulfate radical-based oxidation of TCs may be efficient in
\end{abstract}


environmentally relevant conditions. The antimicrobial potency and ecotoxicological effects of the degradation products warrant further studies.

Keywords: Antibiotics, Persulfate, Sulfate radical, Tetracycline, Thermo activation

\section{Introduction}

Tetracyclines (TCs) are important antibiotics that are widely used in clinical treatment and livestock industry [1]. In China, the annual usage of TCs was about 9413 tons in 1999 [2]. The extensive use of TCs results in its occurrence in the environment via various routines including effluent discharge from wastewater treatment plants (WWTPs), agricultural runoff and disposal of unused drugs $[3,4]$. The most commonly used TCs include tetracycline (TTC), oxytetracycline (OTC) and chlorotetracycline (CTC). The TCs molecules contain connected ring system (labeled as A to D from right to left) with multiple ionizable functional groups that are associated with three macroscopic acid dissociation constants $\left(\mathrm{p} K_{\mathrm{a}}\right)$ (see Fig. 1).

(Fig. 1)

In natural environment, TCs can complex with natural organic matters (NOMs) and minerals, which strongly influence their environmental behavior $[5,6]$. When absorbed on reactive minerals such as manganese oxide $\left(\delta-\mathrm{MnO}_{2}\right)$ and aluminum oxide $\left(\gamma-\mathrm{Al}_{2} \mathrm{O}_{3}\right)$, TCs undergo oxidative transformation [7,8]. Particularly, under oxic condition, complexation of TCs with $\mathrm{Cu}(\mathrm{II}), \mathrm{Fe}(\mathrm{II})$ and $\mathrm{Fe}(\mathrm{III})$ enhances the transformation of these antibiotics $[9,10]$. Direct and indirect photolysis (e.g., photosensitized) are also important pathways for attenuation of TCs in aqueous environment [11,12]. Natural water constituents, such as $\mathrm{Ca}^{2+}, \mathrm{Mg}^{2+}$ or $\mathrm{NO}_{3}^{-}$, affect the photochemical transformation of TCs significantly [13,14]. These natural processes can destruct TCs, leading to the formation of intermediates/products with either increased or decreased toxicity $[11,15]$. 
However, owning to the lower attenuation rate and continuous releasing mode, TCs and their metabolites were frequently detected in sediments [16], surface waters [17] and ground waters [18].

The widespread occurrence of TCs has raised great concerns because these compounds are especially toxic toward aerobic sludge bacteria and microalgae [19]. Long-term, chronic exposure to TCs residues may induce the development of antibiotic resistant genes [4,20,21]. In order to minimize the ecotoxicological effects of TCs, various advanced oxidation processes (AOPs) have been examined, such as radiolysis [22], photo-Fenton [23], photocatalysis [24,25], ozonation [26,27], and chlorination [28,29]. Generally, these AOPs can effectively destroy TCs; however, some intrinsic drawbacks of AOPs hindered their practical application. For instance, ozonation treatment could produce carcinogenic bromate $\left(\mathrm{BrO}_{3}{ }^{-}\right)$if bromide is present [30], and chlorination typically generate highly toxic halogenated intermediates and disinfection by-products (DBPs) [31].

Recently, sulfate radical $\left(\mathrm{SO}_{4}{ }^{-}, \mathrm{SR}\right.$ ) based advanced oxidation processes (SR-AOPs) received a growing interest as efficient and environmentally friendly technologies [32]. The standard redox potential of SR is high $\left(E^{0}=2.5-3.1 \mathrm{~V}\right.$, depending on the $\left.\mathrm{pH}\right)$, and many inorganic and organic compounds react with SR with a second-order rate constant of $10^{6} \sim 10^{9} \mathrm{M}^{-1} \mathrm{~s}^{-1}[33,34]$. SR can be generated via decomposition of persulfate (PS) or peroxymonosufate (PMS) by thermal, ultraviolet, transit mental, base and ultrasound activation [32]. SR-AOPs bear several advantages compared with conventional hydroxyl radical (HO•) based AOPs (HR-AOPs). For example, SR is less likely being consumed by natural organic matters (NOMs) because it reacts predominantly through electron-transfer mechanism [35]. The lifetime of SR is much longer than that of HR in 
aqueous solution (i.e., $300 \mu$ s vs. $~ 40 \mu$ s) [36,37]. The operational pH of SR-AOPs can ranged from acidic to basic [38], whereas for HR-AOPs (e.g., Fenton process), high efficiency only occur at acidic $\mathrm{pH}$ [39]. Furthermore, SR can destruct some recalcitrant pollutants that cannot be readily degraded by HR such as perfluorocarboxylic acids [40].

Currently, efficient degradation of TCs by SR-AOPs have been found in aqueous solution [41-43], soil [44], and sludge [45]. For example, Hou et al. studied the degradation of TTC by ultrasound $/ \mathrm{Fe}_{3} \mathrm{O}_{4} / \mathrm{PS}$ process and reported that $89 \%$ of TTC could be removed at optimal conditions [41]. However, little is known about the transformation mechanisms and pathways of TCs during SR-AOPs although some researchers have observed demethylation, hydroxylation and decarboxylation [42,43]. In this work, we investigated the degradation of TTC by thermo-activated PS oxidation with a special interest focusing on the transformation products and mechanisms. Thermo activation comprises one of the most simply and effective way to produce SR [32]. Understanding the transformation mechanisms and pathways facilitate the practical application of SR-AOPs for remediation of groundwater and soil contaminated by TCs. Kinetic studies were also performed in the present study to better understand the influence factors such as temperature, $\mathrm{pH}$, and water constituents. The degradation of TTC was compared to OTC and CTC to gain insights into the relationship between the chemical reactivity and molecular structures of TCs. Results obtained here may provide important information for understanding SR-based oxidation of antibiotics.

\section{Materials and methods}

\subsection{Chemicals and reagents}

Chemicals, suppliers, and purities are listed in Text S1, Supplementary data. C18 cartridges 
(500mg/6ml, Welchrom) for solid phase extraction (SPE) were purchased from Welch Materials (Shanghai, China). Artificial surface water ASW was prepared according to the reference [46]. The composition of the ASW was described in Table S1, Supplementary data.

\subsection{Experimental setup}

Kinetic reactions were conducted in screw-cap EPA vials with Teflon septa at predetermined temperature controlled by a thermostated water bath (Xianou Instrument Manufacture Co., Ltd, Nanjing). The reaction solution was prepared by adding appropriate volume of antibiotic stock solution $(300 \mu \mathrm{M})$ and PS stock solution $(100 \mathrm{mM})$ into the vials. Solution $\mathrm{pH}$ was adjusted to desired value by $0.01 \mathrm{M} \mathrm{H}_{2} \mathrm{SO}_{4}$ or $\mathrm{NaOH}$. No buffer was used to avoid potential reactions between buffer species and SR. The reaction solution was kept in ice-bathing to avoid any reaction occur during preparation and $\mathrm{pH}$ adjustment. Control experiments without PS or with PS but at ambient temperature $\left(20 \pm 1{ }^{\circ} \mathrm{C}\right)$ were carried out concurrently. In order to investigate the effects of water constituents, ASW was used in comparison to Milli-Q water. Sample aliquots $(0.5 \mathrm{~mL})$ were withdrawn at preselected time point and chilled in an ice bath to stop the reaction and kept in a $4{ }^{\circ} \mathrm{C}$ refrigerator thereafter until further treatment and analysis. All the experiments were carried out in duplicates, and the data were averaged. The standard deviations were usually within 5-10\% unless otherwise stated.

\subsection{Analytical methods}

\subsubsection{HPLC-DAD analysis}

Concentrations of tetracycline antibiotics were measured by a Hitachi L-2000 high performance liquid chromatography equipped with an L-2455 diode array detector (HPLC-DAD). Detailed HPLC analytical parameters can be found in Table. S2, Supplementary data. 
Quantification of the antibiotics was based on multipoint standard calibration.

\subsubsection{SPE extraction}

For products identification, $100 \mathrm{~mL} 30 \mu \mathrm{M}$ TTC and $2 \mathrm{mM}$ PS was allowed to react for 180

min under $50{ }^{\circ} \mathrm{C}$. The reaction solution was then chilled and enriched by SPE using $\mathrm{C} 18$ cartridges. Detailed experimental procedures are given in Text S2, Supplementary data.

\subsubsection{LC-MS/MS analysis}

Reaction products were identified by liquid chromatography-electrospray ionization-triple quadrupole mass spectrometry (HPLC-ESI-MS/MS), consisting of an Agilent 1200 series HPLC and a G6410B triple quadrupole mass spectrometer. Chromatographic separation was accomplished using an Agilent ZORBAX Eclipse Plus C18 column $(3.5 \mu \mathrm{m}, 150 \mathrm{~mm} \times 2.1 \mathrm{~mm}$ I.D.). The analytical details are presented in the Text S3, Supplementary data. Instrument control, data acquisition and processing were performed using the associated Agilent Mass Hunter Qualitative analysis software (version B.04.00).

\subsection{4. $U V$-vis spectrum and $\mathrm{pH}$ measurement}

The UV-vis absorption spectrum of TTC reaction solution was recorded by a Cary 50 Conc UV-visible spectrophotometer (Varian, CA). Solution pH was measured by an E-201-C combined glass electrode (Leici, Shanghai) connected to a PHS-3E microprocessor $\mathrm{pH} / \mathrm{mV}$ meter (BANTE instrument)

\section{Results and discussion}

\subsection{Preliminary experiments}

No loss of TTC was observed by heating the TTC solution for $240 \mathrm{~min}$ (Fig. S1, Supplementary data), indicating TTC was thermally stable and hydrolysis-resistant at $50{ }^{\circ} \mathrm{C}$. 
Without heating, TTC was also stable in the presence of PS at $\mathrm{pH} 4.0$, indicating ambient temperature $\left(20 \pm 1{ }^{\circ} \mathrm{C}\right)$ could not activate PS to oxidize TTC under acidic condition. However, at $\mathrm{pH} 7.0$, approximately $20 \%$ of TTC was destructed in the presence of PS at ambient temperature. This finding is somewhat unexpected and interesting. It was reported that quinone and phenoxide species could chemically active PS to produce SR $[47,48]$. Since the structure of TTC contains these functional moieties at neutral $\mathrm{pH}\left(\mathrm{p} K_{\mathrm{a} 1}=3.3, \mathrm{p} K_{\mathrm{a} 2}=7.7, \mathrm{p} K_{\mathrm{a} 3}=9.7\right)$, it was likely that PS was activated by TTC itself. Such activation was expected to be pH-dependent. However, further studies are needed to confirm this hypothesis and decipher the underlying mechanisms.

On the other hand, thermo-activated PS can effectively destroy TTC, especially at neutral $\mathrm{pH}$ (Fig. S1). The SR produced by thermo-activated PS decomposition is highly reactive and prone to react with electron-rich compounds through electron-transfer mechanism [32-34]. The molecule of TTC contains electron-rich moieties (ERMs) such as dimethylamino, phenolic, and conjugated double-bonds; thus, these moieties are likely susceptible to the electrophilic attacks of SR [28].

\subsection{Temperature- and $\mathrm{pH}$-dependent reaction kinetics}

As expected, increasing the temperature markedly enhanced the degradation of TTC by thermo-activated PS oxidation (Fig. 2A). Approximately $70 \%$ TTC was degraded after 240 min at $40{ }^{\circ} \mathrm{C}$; whereas TTC was completely eliminated within $30 \mathrm{~min}$ at $70{ }^{\circ} \mathrm{C}$. Higher temperature promoted the activation of PS and enhanced the formation rate of SR [32], which favored the degradation of TTC. Furthermore, the chemical reactions initiated by radical attack were significantly elevated at higher temperature according to thermodynamic law. The degradation of TTC at different temperature was found to follow pseudo-first-order reaction kinetics (Eq. (1)). Values of pseudo-first-order rate constants $\left(k_{\mathrm{obs}}\right)$ were obtained by linear regression of 
$\ln \left([\mathrm{TTC}]_{\mathfrak{t}} /[\mathrm{TTC}]_{0}\right)$ vs. time plots for each reaction (Table S3, Supplementary data). It should be noted that higher temperature may also facilitate the reactions of radical-radical and radical-nontarget species, consequently lowering the removal efficiency of target pollutant [32]. Previous studies have demonstrated that higher temperature decreased the reaction stoichiometric efficiency (RSE), which was defined as the number of pollutant degraded vs. the number of PS consumed over a specific time interval [32].

$$
\begin{aligned}
& \ln \left(\frac{[\mathrm{TTC}]_{\mathrm{t}}}{[\mathrm{TTC}]_{0}}\right)=-k_{\mathrm{obs}} \mathrm{t} \\
& \ln k_{\mathrm{obs}}=\ln \mathrm{A}-\frac{E_{\mathrm{a}}}{\mathrm{R} T}
\end{aligned}
$$

The temperature-dependence of $k_{\mathrm{obs}}$ was further evaluated by Arrhenius equation (Eq. (2)). Where $A$ is the pre-exponential factor, $E_{\mathrm{a}}$ is the apparent activation energy $\left(\mathrm{kJ} \mathrm{mol}^{-1}\right), \mathrm{R}$ is the universal gas constant $\left(8.314 \mathrm{~J} \mathrm{~mol}^{-1} \mathrm{~K}^{-1}\right)$, and $T$ is the absolute temperature. Fig. $2 \mathrm{~B}$ showed a linear relationship between $\ln \left(k_{\mathrm{obs}}\right)$ and $1 / T$, and the slope value of the line was used to calculate the value of $E_{\mathrm{a}}$ for TTC oxidation. The $E_{\mathrm{a}}$ value was determined to be $70.48 \pm 1.13 \mathrm{~kJ} \mathrm{~mol}^{-1}$.

(Fig. 2)

The value of $E_{\mathrm{a}}$ of tetracycline oxidation by thermo-activated PS system was compared with other compounds previously reported [49-56] (see Table 1). As seen, the $E_{\mathrm{a}}$ of TTC was comparatively lower than those of other organic compounds previously reported (e.g., sulfamethoxazole and trimethoprim) [49,50]. The discrepancy reflects the difference in molecular structures and the susceptibility of SR oxidation of these compounds. Results obtained here further supported the fact that TTC was more labile for SR oxidation due to its conjugated ring systems with higher electron density. 
The degradation of TTC showed a pH dependency, and $k_{\mathrm{obs}}$ increased markedly with increasing $\mathrm{pH}$ (Fig. 3). Since TTC has three $\mathrm{p} K_{\mathrm{a}}$, this result suggested that the deprotonated, non-dissociated TTC was more reactive for SR attack. Khad et al. investigated the ozonation of TTC and suggested that the protonated, dissociated form of TTC would decrease the electron densities on the $\mathrm{C} 2-\mathrm{C} 3$ double bond, the amide and the carbonyl groups at $\mathrm{C} 1$ via conjugation, thus, reducing the probability of ozone attack at these sites [26]. Our result also implied that the phenolate form of phenolic-diketone group and the unprotonated dimethylamino moiety were more reactive, most likely due to the higher electron densities of these moieties which favored the electrophilic attack of SR. Similar result has been reported by Liu et al. that the deprotonated form of OTC had a higher reactivity toward SR than those of protonated and zwitterionic forms of OTC [43].

(Fig. 3)

\subsection{Intermediate products}

UV-vis absorbance spectrum of TTC in aqueous solution shows two absorbance bands with one at $250-300 \mathrm{~nm}$ corresponding to the tricarbonyl-amide moiety and the other at $340-400 \mathrm{~nm}$ corresponding to the phenolic-diketone moiety [8,9]. The UV-vis absorption spectrum of tetracycline solution changed over the time course of oxidation by thermo-activated PS process (Fig. S2 of Supplementary data). The intensity of the characteristic absorption peaks decreased as the reaction proceeded, implying the destruction of the conjugation system of TTC molecule.

The transformation products (TPs) of TTC were enriched by SPE and then identified by LC-MS/MS technique. Full scan mass spectrum of the concentrated TTC degradation solution 
revealed several products with mass-to-charge ratio $(\mathrm{m} / \mathrm{z})$ differed from that of TTC $(\mathrm{m} / \mathrm{z}=445)$, suggesting the formation of TPs (Fig. S2, Supplementary data). Further MS/MS analysis under product ion scan mode was conducted for the structural elucidation of the TPs (Fig. S3 and Table S4, Supplementary data). Totally, we tentatively identified seven TPs with $\mathrm{m} / z$ of $431,417,461$, 459 and 427, 475 and 491, respectively. Possible molecular structures of these TPs are described in Fig. 4. Among them, $\mathrm{m} / \mathrm{z} 431$ and 417 were identified as the 4-demethyltetracycline and 4-dedimethyltetracycline, respectively. The $\mathrm{m} / \mathrm{z} 461$ and 459 were assigned as the mono-hydroxylated TTC and its quinoid-type compound, respectively. The $m / z 427$ was proposed as the 5a,6-anhydro-tetracycline (i.e., anhydroxylTTC, AHTTC). The $m / z 475$ was proposed as the hydroxylation product of $\mathrm{m} / \mathrm{z} 459$, and $\mathrm{m} / \mathrm{z}, 491$ was assumed to be the hydroxylation product of $m / z 475$.

\section{(Fig. 4)}

\subsection{Mechanisms and pathways}

The identified products of TTC indicated that $N$-demethylation occurred by stepwise attack of SR, leading to the formation of 4-demethyltetracycline and 4-dedimethyltetracycline, sequentially. Since dimethylamino group ( $N$-dimethyl) is a typical auxochromophore, $N$-dealkylation can cause hypsochromic shift in UV-vis absorbance of the parent compound [57]. This hypothesis was supported by the changes in UV-vis absorbance spectrum of TTC solution after degradation (Fig. S2, Supplementary data). As seen, the absorbance band at 250-300 nm corresponding the TTC's tricarbonylamide group (A ring) shifted to lower wavelength (i.e., hypsochromic shift) after degradation, consistent with the $N$-demethylation reaction. Previous studies have reported the hypsochromic shift for $N$-demethylation of dyes such as crystal violet 
during photocatalytic degradation [58]. $N$-dealkylation has also been observed during SR-based oxidative degradation of atrazine [35,52,59] and methylene blue [60].

The $N$-demethylation was initiated by transferring one electron from the lone electron pair of amine- $\mathrm{N}$ to SR, resulting in the aminium radical cation. Further deprotonation of $\alpha-\mathrm{C}$ led to the formation of a carbon-centered radical. The C-centered radical reacted rapidly with dissolve oxygen to produce a peroxyl radical. Further loss a superoxide radical $\left(\mathrm{O}_{2}{ }^{\circ}\right)$ yield an iminium cation. It is well-known that imine is chemically unstable in aqueous solution and may undergo hydrolysis quickly, producing the aforementioned $N$-demethylation product [61]. Detail mechanisms describing the $N$-demethylation of TTC during SR oxidation was proposed in Scheme A of Fig. 5. Subsequently, similar $N$-demethylation occurred again, generating $N$-dedimethylation product (i.e., 4-dedimethyltetracycline). The dimethylamino moiety of TTC has previously been identified as the reactive site for electrophilic attack of free chlorine $(\mathrm{HOCl})$ [10], and $N$-demethylation products of TTC have been observed during photolysis [11,14] and photocatalysis $[24,25]$. It has been proposed that the nearby tricarbonyl-amide group can provide resonance stabilization for the cationic imine intermediate generated [22]. Similar $N$-dealkylation mechanism has previously been proposed by Chen and Huang for $\delta-\mathrm{MnO}_{2}$ mediated oxidative transformation of TTC [7], and by Luiz et al. for ozone reactions with erythromycin [61].

(Fig. 5)

SR is an electrophilic species and prone to react with electro-rich moieties (ERMs) of organic compounds, resulting in the formation of SR-adduct intermediates or radical cations [33,34]. These radicals/intermediates may undergo hydrolysis, producing HR-adduct intermediates (e.g., hydroxycyclohexadienyl radical) that can be formed by HR direct addition as well [62]. Thus, the 
$\mathrm{C}=\mathrm{C}$ double bond and phenolic moiety in TTC molecule are the likely sites toward SR attack. Potential reactive sites may include $\mathrm{C} 2-\mathrm{C} 3$ keto-enol moiety, $\mathrm{C} 7, \mathrm{C} 9$, and $\mathrm{C} 11 \mathrm{a}-\mathrm{C} 12$ double bond (see Fig. 1 for numbered positions). Unfortunately, the mass spectrum data did not allow us to distinguish which site SR preferentially attacked and the exact position that hydroxylation occurred. Additional experiment such as C13 study should be carried out to gain more insight into the mechanism of TTC degradation, but unfortunately the C13 standard of TTC is not available. The second-order rate constant for reactions between SR and some structurally related moieties are available in literature. For example, $8.8 \times 10^{9},(1.6-2.0) \times 10^{8}, 7.7 \times 10^{8}$, and $1.1 \times 10^{9} \mathrm{M}^{-1} \mathrm{~s}^{-1}$ for phenol, acrylamide, crotonic acid, and methacrylic acid, respectively [34].<smiles>Oc1ccccc1</smiles>

Phenol<smiles>C/C=C/C(=O)O</smiles>

Crotonic acid<smiles>CC(C)=O</smiles><smiles>C/C=C\C(=O)O</smiles>

Methacrylic acid

Based on this information, we assumed that hydroxylation most likely occurred at $\mathrm{C} 7$ position of the phenolic ring. This hypothesis was in agreement with a recent study that the phenolic ring (D ring) of OTC was the preferential site for SR attack [43]. Jeong and co-workers proposed that HR attacked at this position was benefit for the stabilization of a reaction intermediate via the formation of intermolecular hydrogen bond [22]. Such intermediate might underwent $\mathrm{O}_{2}$ addition and $\mathrm{HO}_{2} \bullet$ dissolution, generating hydroxylated TTC [22]. The hydroxylated TTC further underwent a two-electron-transfer oxidation step, producing the corresponding quinoid-type compound. Detail mechanisms accounting for the formation of hydroxylated TTC and 
quinoid-type derivative was displayed in Scheme B of Fig. 5. The formation of quinoid-type compound is consistent with the yellow-brown color of the treated TTC solution (data not shown). The UV-vis absorption spectrum of TTC reaction solution showed a bathochromic shift of the absorbance at $340-380 \mathrm{~nm}$ and the absorbance at $>400 \mathrm{~nm}$ was significantly increased (Fig. S2, Supplementary data). These findings also provided further evidence for the formation of quinoid-type compound.

Dehydration of TTC resulted in the formation of AHTTC. Liu et al. proposed that the most likely reaction site for dehydration was $\mathrm{C} 6$ because of the tautomerization of $\mathrm{C} 11-\mathrm{C} 12$ keto-enol led to the formation of a stable second aromatic ring [43]. AHTTC has previously been identified as the major photoproduct of TTC [63]. It has been proposed that acidic condition favors the formation of AHTTC by dehydration of the hydrogen at C5a position and the hydroxyl group at C6 position [19]. Thus, it is unclear whether the formation of AHTTC is a result of SR attack or the acidified solution caused by PS decomposition. Nevertheless, the transformation products identified herein are consistent with a recent study in which hydroxylation, $N$-demethylation and dehydration have been observed during UV-activated persulfate oxidation of OTC [43].

SR-based oxidation of TTC might produce ring-opening products with lower molecular weights. These compounds were, however, not observed in the present study. Previous studies have reported the cleavage of carboatomic and naphthol ring of TTC during photocatalytic degradation [25]. Further studies are needed to elucidate if these ring-opening products were generated in SR-AOPs as well.

\subsection{Evolution patterns of intermediate products}

LC-MS/MS analysis under single ion monitoring mode (SIM) was used to study the 
evolution pattern of the intermediate products due to its high selectivity and sensitivity. However, only $m / z 417,217$ and 459 could be detected, probably due to their low yield and/or further transformation. The evolution pattern showed in Fig. 6 revealed that these products were produced at the initial stage of the reaction and then further transferred as the reaction progressed. This result indicated that these intermediates were also susceptible to oxidation by SR and less likely to build up in the reaction solution. However, due to the lack of authentic standards, an accurate quantification of these products was impossible. The much higher intensity of $m / z 459$ in Fig. 6 possibly implied that Scheme B of Fig. 5 was an important degradation pathway.

(Fig. 6)

\subsection{Comparison with OTC and CTC}

In order to investigate the effect of structural difference on TCs degradation, the reaction kinetic of TTC was compared with OTC and CTC (Fig. 7). As seen, OTC was thermally unstable in the absence of PS, and approximately $40 \%$ of OTC was removed in 30 min. No further loss of OTC was observed as the reaction was preceded up to $240 \mathrm{~min}$. OTC was degraded much more quickly than TTC in the presence of PS which may be ascribed to the presence of a hydroxyl group at C5 position. The additional hydroxyl group was known to make the molecule of OTC unique and was expected to enhance the electron density of the conjugated ring system, which favored the electrophilic attack of SR [19]. The higher reactivity of OTC observed was also likely resulted from the longer lifetime of the transient intermediates produced by SR attack [22]. Jeong et al. observed that the maximum absorbance of the transient spectra for TTC and OTC were 50 and $100 \mu \mathrm{s}$, respectively [22]. It is well-known that the longer lifetime the transient intermediate is, the higher possibility it is further transferred to products instead of back-transferred to parent 
compounds. The higher reactivity of OTC was consistent with a recent study reporting rapid elimination of OTC by UV/PS process [43].

(Fig. 7)

For CTC, extremely fast degradation was observed with $30 \mu \mathrm{M}$ CTC being completely removed in $30 \mathrm{~min}$ in the presence of PS (Fig. 7). We assumed that the degradation of CTC should be slower than that of TTC due the electron withdrawing effect of the chlorine substituent at C7 position. However, the highly conjugated ring system may lower the substituent effect [19]. Addition experiment also showed that CTC was quickly transferred at $50{ }^{\circ} \mathrm{C}$ in the absence of PS, probably due to thermolysis. Therefore, the fast degradation of CTC was expected to be a combined result of thermolysis and radical-based oxidation.

\subsection{Degradation in artificial surface water}

In order to investigate if the results obtained here could be extrapolated to environmentally relevant conditions, the degradation of TTC was performed in ASW. The composition of the ASW resembled those of hard fresh surface water [46]. Surprisingly, the degradation of TTC was substantially enhanced in ASW compared to Milli-Q water (Fig. 8). The enhanced degradation of TTC in ASW was unexpected and interesting because the inorganic and organic species present in the ASW (e.g., $\mathrm{HCO}_{3}{ }^{-}, \mathrm{Cl}^{-}, \mathrm{NO}_{3}{ }^{-}, \mathrm{NOM}$ ) were capable of scavenging SR and $\mathrm{HR}$, thus lowering the degradation efficiency.

(Fig. 8)

TTC has a strong tendency to complex with metal ions in aqueous solution, which remarkably influence its environmental fate [10,13]. Solution $\mathrm{pH}$ is an important factor determining the speciation of TTC and its complexation [10,13]. It has been reported that $\mathrm{HTTC}^{-}$ 
and $\mathrm{TTC}^{2-}$ are two species of TTC that can complex with $\mathrm{Ca}^{2+}$ and $\mathrm{Mg}^{2+}$ in hard waters [13].

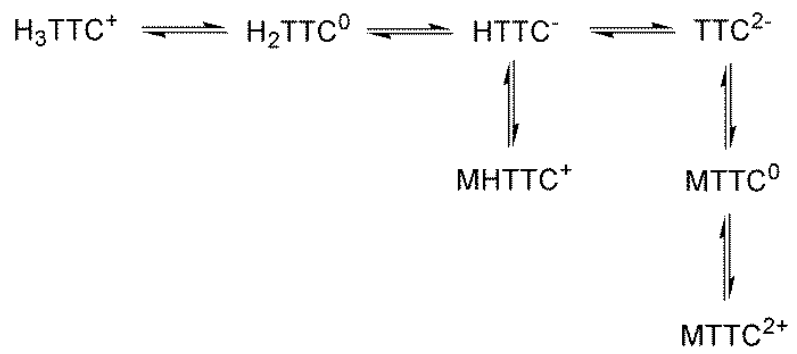

Werner et al. have proposed that the complexation of TTC with metal ions can change the macroscopic acid-base dissociation constants [13]. The increased TTC acidity due to complexation with metal ions led to the formation of more deprotonated, non-dissociated form of TTC, which was found to be more reactive for SR attack (Fig. 3). The increased degradation of TTC in ASW may also be explained by the formation of secondary reactive species such as $\mathrm{CO}_{3}{ }^{-}$, $\mathrm{Cl}_{2}{ }^{\circ}, \mathrm{NO}_{3}{ }^{\circ}$ (Eqs. (3-7)) [34].

$$
\begin{aligned}
& \mathrm{SO}_{4}^{--}+\mathrm{HCO}_{3}^{-} \rightarrow \mathrm{SO}_{4}^{2-}+\mathrm{HCO}_{3}^{\bullet}, k=1.6 \times 10^{6} \mathrm{M}^{-1} \mathrm{~s}^{-1}(\text { at } \mathrm{pH}=8.4) \\
& \mathrm{HCO}_{3}^{\bullet} \leftrightarrow \mathrm{H}^{+}+\mathrm{CO}_{3}^{--}, \mathrm{p} K_{\mathrm{a}}<0 \\
& \mathrm{SO}_{4}^{\bullet-}+\mathrm{Cl}^{-} \leftrightarrow \mathrm{SO}_{4}^{2-}+\mathrm{Cl}^{\bullet}, k_{f}=(3.2 \pm 0.2) \times 10^{8} \mathrm{M}^{-1} \mathrm{~s}^{-1} ; k_{r}=(2.1 \pm 0.1) \times 10^{8} \mathrm{M}^{-1} \mathrm{~s}^{-1}
\end{aligned}
$$

$$
\begin{aligned}
& \mathrm{Cl}^{\bullet}+\mathrm{Cl}^{-} \leftrightarrow \mathrm{Cl}_{2}^{\bullet-}, k_{f}=(7.8 \pm 0.8) \times 10^{9} \mathrm{M}^{-1} \mathrm{~s}^{-1} ; k_{r}=(5.7 \pm 0.4) \times 10^{4} \mathrm{M}^{-1} \mathrm{~s}^{-1}(6) \\
& \mathrm{SO}_{4}^{\bullet-}+\mathrm{NO}_{3}^{-} \rightarrow \mathrm{SO}_{4}^{2-}+\mathrm{NO}_{3}^{\bullet}, k=2.1 \times 10^{0} \mathrm{M}^{-1} \mathrm{~s}^{-1}
\end{aligned}
$$

These secondary reactive species are generally less reactive than SR or HR, and only reactive with electron rich compounds. However, since TTC possesses conjugated ring system with high electron density and the steady-state concentrations of secondary reactive species are usually high, it is reasonable that these species might contribute largely to the degradation of TTC. However, additional experiments are needed to fully elucidate the underlying mechanisms leading the observed fast degradation of TTC in ASW. 


\subsection{Environmental implications}

SR is an electrophilic species and prone to attack the ERMs of organic compounds. Since these moieties are usually the microbial reactive sites of antibiotics, the attack of SR would result in the loss of antimicrobial potency. For example, Richman and Mezyk found that SR based oxidation of $\beta$-lactam antibiotics mainly occurred at sulfur atom and double bond adjacent to the $\beta$-lactam core, which significantly remove the antimicrobial activity [64]. A similar scenario likely occurred in SR based oxidation of TCs. The C1-C4 positions in the tricarbonyl-amide group and the $\mathrm{C} 10-\mathrm{C} 12$ positions in the phenolic-diketone group are believed to be the critical sites in the effectiveness of TCs [7,8]. Therefore, destruction of these moieties by SR is expected to eliminate the antimicrobial activities of TCs, e.g., the $N$-demethylation products. The formation of AHTTC should be taken into consideration, however, since previous studies have confirmed that such compound is more toxic than parent compound [65] because it has a different mode of action than the parent TTC by being bactericidal instead of bacteriostatic [19]. Therefore, further ecotoxicological studies are highly desirable before SR-AOPs are utilized for remediation of soils and/or waters contaminated by TCs.

\section{Conclusions}

Thermo-activated PS process was efficient for destructing TCs in aqueous solution. Increasing the temperature and solution $\mathrm{pH}$ favored the removal of TTC. The degradation of TTC mainly proceeded through $\mathrm{N}$-demethylation, hydroxylation-oxidation and dehydration, leading to the formation of several intermediates which was tentatively identified by solid phase extraction-liquid chromatography-tandem mass spectrometry. CTC and OTC were more labile than TTC for degradation, highlighting the structure-specific reactivity of TCs. TTC was degraded 
more quickly in ASW than that in Milli-Q water, suggesting that the natural water constituents may facilitate the degradation of TCs by SR-AOPs. Further studies are needed to elucidate the antimicrobial potency and ecotoxicological effects of the intermediate products.

\section{Notes}

The authors declare no competing financial interest.

\section{Acknowledgements}

This work was supported by China Postdoctoral Research Funds (2015M570454), National Science Foundation of China (51578294), Jiangsu Planned Projects for Postdoctoral Research Funds (1402013A), Fundamental Research Funds for the Central Universities (KYZ201407), and the Priority Academic Program Development (PAPD) of Jiangsu Higher Education Institute.

\section{Appendix A. Supplementary Data}

The composition of artificial surface water (ASW) (Table S1); Detailed description of chemicals and regents (Text S1), the SPE procedure (Text S2), HPLC-DAD analysis (Table S2), and LC-MS/MS analysis (Text S3); Results of preliminary experiments (Fig. S1); Results of TTC degradation under different temperature (Table S3); Changes in the UV-vis spectrum of the reaction solution and full scan mass spectra of the SPE-concentrated reaction solution (Fig. S2); Product ion scan mass spectrum data of the transformation products (Table S4); Product ion scan mass spectra of TTC transformation products (Fig. S3). Supplementary data associated with this article can be found, in the online version.

\section{References}

[1] A.K. Sarmah, M.T. Meyer, A.B.A. Boxall, A global perspective on the use, sales, exposure pathways, occurrence, fate and effects of veterinary antibiotics (Vas) in the environment, Chemosphere 65 (2006) 725-759. 
[2] N. Wu, M. Qiao, B. Zhang, W. Cheng, Y. Zhu, Abundance and diversity of tetracycline resistance genes in soils adjacent to representative swine feedlots in China, Environ. Sci. Technol. 44 (2010) 6933-6939.

[3] R. Daghrir, P. Drogui, Tetracycline antibiotics in the environment: a review, Environ. Chem. Lett. 11 (2013) 209-227.

[4] A. Boxall, D. Kolpin, B. Holling-Sorensen, J. Tolls, Are veterinary medicines causing environmental risks?, Environ. Sci. Technol. 37 (2003) 287A-294A.

[5] C. Gu, K.G. Karthikeyan, Interaction of tetracycline with aluminum and iron hydrous oxides, Environ. Sci. Technol. 39 (2005) 2660-2667.

[6] C. Gu, K.G. Karthikeyan, S.D. Sibley, J.A. Pedersen, Complexation of the antibiotic tetracycline with humic acid, Chemosphere 66 (2007) 1494-1501.

[7] W.-R. Chen, C.-H. Huang, Transformation kinetics and pathways of tetracycline antibiotics with manganese oxide, Environ. Pollut. 159 (2011) 1092-1100.

[8] W.-R. Chen, C.-H. Huang, Adsorption and transformation of tetracycline antibiotics with aluminum oxide, Chemosphere 79 (2010) 779-785.

[9] W.-R. Chen, C.-H. Huang, Transformation of tetracyclines mediated by $\mathrm{Mn}$ (II) and $\mathrm{Cu}(\mathrm{II})$ ions in the presence of oxygen, Environ. Sci. Technol. 43 (2009) 401-407.

[10] H. Wang, H. Yao, P. Sun, D. Li, C.-H. Huang, Transformation of tetracycline antibiotics and Fe(II)/Fe(III) species induced by their complexation, Environ. Sci. Technol. DOI: 10.1021/acs.est.5b03696.

[11] S. Jiao, S. Zheng, D. Yin, L. Wang, L. Chen, Aqueous photolysis of tetracycline and toxicity of photolytic products to luminescent bacteria, Chemosphere 73 (2008) 377-382.

[12] Y. Chen, C. Hu, J. Qu, M. Yang, Photodegradation of tetracycline and formation of reactive oxygen species in aqueous tetracycline solution under simulated sunlight irradiation, J. Photochem. Photobiol. A Chem. 197 (2008) 
81-87.

[13] J.J. Werner, W.A. Arnold, K. McNeill, Water hardness as a photochemical parameter: tetracycline photolysis as a function of calcium concentration, magnesium concentration, and pH, Environ. Sci. Technol. 40 (2006) 7236-7241.

[14] J. Niu, Y. Li, W. Wang, Light-source-dependent role of nitrate and humic acid in tetracycline photolysis: kinetics and mechanism, Chemosphere 92 (2013) 1423-1429.

[15] K.H. Wammer, M.T. Slattery, A.M. Stemig, J.L. Ditty, Tetracycline photolysis in natural waters: loss of antibacterial activity, Chemosphere 85 (2011) 1505-1510.

[16] L.-J. Zhou, G.-G. Ying, J.-L. Zhao, J.-F. Yang, L. Wang, B. Yang, S. Liu, Trends in the occurrence of human and veterinary antibiotics in the sediments of the Yellow River, Hai River and Liao River in northern China, Environ. Pollut. 159 (2011) 1877-1885.

[17] A. Jia, Y. Xiao, J. Hu, M. Asami, S. Kunikane, Simultaneous determination of tetracyclines and their degradation products in environmental waters by liquid chromatography-electrospray tandem mass spectrometry, $\mathrm{J}$. Chromatogr. A 1216 (2009) 4655-4662.

[18] K.G. Karthikeyan, M.T. Meyer, Occurrence of antibiotics in wastewater treatment facilities in Wisconsin, USA, Sci. Total Environ. 361 (2006) 196-207.

[19] B. Halling-Sørensen, G. Sengeløv, J.Tjørnelund, Toxicity of tetracyclines and tetracycline degradation prodcuts to environmentally relevant bacteria, including selected tetracycline-resistant bacteria, Arch. Environ. Contam. Toxicol. 42 (2002) 263-271.

[20] A. Pruden, R. Pei, H. Storteboom, K.H. Carlson, Antibiotic resistance genes as emerging contaminants: studies in Northern Colorado, Environ. Sci. Technol. 40 (2006) 7445-7450.

[21] K. Kümmerer, Antibiotics in the aquatic environment-a review-Part II, Chemosphere 75 (2009) 435-441. 
[22] J. Jeong, W. Song, W.J. Cooper, J. Jung, J, Greaves, Degradation of tetracycline antibiotics: mechanisms and kinetic studies for advanced oxidation/reduction processes, Chemosphere 78 (2010) 533-540.

[23] I. Rossi Bautitz, R.F. Pupo Nogueira, Degradation of tetracycline by photo-Fenton process-solar irradiation and matrix effects, J. Photochem. Photobiol. A Chem. 187 (2007) 33-39.

[24] X.-D. Zhu, Y.-J. Wang, R.-J. Sun, D.-M. Zhou, Photocatalytic degradation of tetracycline in aqueous solution by nanosized $\mathrm{TiO}_{2}$, Chemosphere 92 (2013) 925-932.

[25] J. Niu, S. Ding, L. Zhang, J. Zhao, C Feng, Visible-light-mediated $\mathrm{Sr}_{-} \mathrm{Bi}_{2} \mathrm{O}_{3}$ photocatalysis of tetracycline: Kinetics mechanisms and toxicity assessment, Chemosphere 93 (2013) 1-8.

[26] M.H. Khan, H. Bae, J.-Y. Jung, Tetracycline degradation by ozonation in the aqueous phase: proposed degradation intermediates and pathway, J. Hazard. Mater. 181 (2010) 659-665.

[27] I. Dalmázio, M.O. Almeida, R. Augusti, Monitoring the degradation of tetracycline by ozone in aqueous medium via atmospheric pressure ionization mass spectrometry, J. Am. Soc. Mass Spectrom 18 (2007) 679-687.

[28] P. Wang, Y.-L. He, C.-H. Huang, Reactions of tetracycline antibiotics with chlorine dioxide and free chlorine, Water Res. 45 (2011) 1838-1846.

[29] Y. Wan, A. Jia, Z. Zhu, J. Hu, Transformation of tetracycline during chloramination: kinetics, products and pathways, Chemosphere 90 (2013) 1427-1434.

[30] U. von Gunten, Ozonation of drinking water: Part II. Disinfection and by-product formation in presence of bromide, iodide or chlorine, Water Res. 37 (2003) 1469-1487.

[31] M. Deborde, U. von Gunten, Reaction of chlorine with inorganic and organic compounds during water treatment-kinetics and mechanisms: a critical review, Water Res. 42 (2008) 13-51.

[32] A. Tsitonaki, B. Petri, M. Crimi, H. Mosbæk, R.L. Siegrist, P.L. Bjerg, In situ chemical oxidation of contaminated soil and groudwater using persulfate: A review, Crit. Rev. Environ. Sci. Technol. 40 (2010) 55-91. 
[33] P. Neta, V. Madhavan, H. Zemel, R.W. Fessenden, Rate constants and mechanism of reaction of $\mathrm{SO}_{4}{ }^{-{ }^{-}}$with aromatic compounds, J. Am. Chem. Soc. 99 (1977) 163-164.

[34] P. Neta, R.E. Huie, A.B. Ross, Rate constants for reactions of inorganic radicals in aqueous solution, J. Phys.

Chem. Ref. Data 17(3) (1988) 1027-1284.

[35] H.V. Lutze, S. Bircher, I. Rapp, N. Kerlin, R. Bakkour, M. Geisler, C. von Sonntag, T. C. Schmidt, Degradation of chlorotriazine pesticides by sulfate radicals and the influence of organic matter, Environ. Sci. Technol. 49 (2015) 1673-1680.

[36] L. Dogliotti, E. Hayon, Flash photolysis of persulfate ions in aqueous solutions. Study of the sulfate and ozonide radical anions, J. Phys. Chem. 71 (1967) 2511-2516.

[37] J.M. Burns, W.J. Cooper, J.L. Ferry, D. Whitney King, B.P. DiMento, K. McNeill, C.J. Miller, W.L. Miller, B.M. Peake, S.A. Rusak, A.L. Rose, T. David Waite, Methods for reactive oxygen species (ROS) detection in aqueous environments, Aquat. Sci. 74 (2012) 683-734.

[38] Y.-H. Guan, J. Ma, X.-C. Li, J.-Y. Fang, L.-W. Chen, Influence of pH on the formation of sulfate and hydroxyl radicals in the UV/peroxymonosulfate system, Environ. Sci. Technol. 45 (2011) 9308-9314.

[39] J.J. Pignatello, E. Oliveros, A. MacKay, Advanced oxidation processes for organic contaminant destruction based on the Fenton reaction and related chemistry, Crit. Rev. Environ. Sci. Technol. 36 (2006) 1-84.

[40] H. Hori, Y. Nagaoka, M. Murayama, S. Kutsuna, Efficent decomposition of perfluorocarboxylic acids and alternative fluorochemical surfactants in hot water, Environ. Sci. Technol. 42 (2008) 7438-7443.

[41] L. Hou, H. Zhang, X. Xue, Ultrasound enhanced heterogeneous activation of peroxydisulfate by magnetite catalyst for the degradation of tetracycline in water, Sep. Purif. Technol. 84 (2012) 147-152.

[42] G. Hossein Safari, S. Nasseril, A. Hossein Mahvi, K. Yaghmaeian, R. Nabizadeh, M. Alimohammadi, Optimization of sonochemical degradation of tetracycline in aqueous solution using sono-activated persulfate 
process, J. Environ. Health Sci. Eng. 13:76 (2015) 1-15.

[43] Y. Liu, X. He, Y. Fu, D.D. Dionysiou, Kinetics and mechanism investigation on the destruction of oxytetracycline by UV-254 nm activation of persulfate, J. Hazard. Mater. 305 (2016) 229-239.

[44] M. Ötker Uslu, I. Akmehmet Balcioglu, Simultaneous removal of oxytetracycline and sulfamethazine antibacterials from animal waste by chemical oxidation processes, J. Agric. Food Chem. 57 (2009) 11284-11291.

[45] N. Bilgin Oncu, N. Mercan, I. Akmehmet Balcioglu, The impact of ferrous iron/heat-activated persulfate treatment on waste sewage sludge constituents and sorbed antimicrobial micropollutants, Chem. Eng. J. 259 (2015) 972-980.

[46] L. Tong, P. Eichhorn, S. Pérez, Y. Wang, D. Barceló, Photodegradation of azithromycin in various aqueous systems under simulated and natural solar radiation: kinetics and identification of photoproducts, Chemosphere 83 (2011) $340-348$.

[47] G. Fang, J. Gao, D.D. Dionysiou, C. Liu, D. Zhou, Activation of persulfate by quiniones: free radical reactions and implication for the degradation of PCBs, Environ. Sci. Technol. 47 (2013) 4605-4611.

[48] M. Ahmad, A.L. Teel, R.J. Watts, Mechanism of persulfate activation by phenols, Environ. Sci. Technol. 47 (2013) 5861-5871.

[49] Y. Ji, Y. Fan, K. Liu, D. Kong, J. Lu, Thermo activated persulfate oxidation of antibiotic sulfamethoxazole and structurally related compounds, Water Res. 87 (2015) 1-9.

[50] Y. Ji, W. Xie, Y. Fan, Y. Shi, D. Kong, J. Lu, Degradation of trimethoprim by thermos-activated persulfate oxidation: raction kinetics and transformation mechanisms, Chem. Eng. J. 286 (2016) 16-24.

[51] R.H. Waldemer, P.G. Tratnyek, R.L. Johnson, J.T. Nurmi, Oxidation of chlorinated ethenes by heat-activated persulfate: Kinetics and products, Environ. Sci. Technol. 41 (2007) 1010-1015.

[52] Y. Ji, C. Dong, D. Kong, J. Lu, Q. Zhou, Heat-activated persulfate oxidation of atrazine: implications for 
remediation of groundwater contaminated by herbicides, Chem. Eng. J. 263 (2015) 45-54.

[53] C. Tan, N. Gao, Y. Deng, N. An, J. Deng, Heat-activated persulfate oxidation of diuron in water, Chem. Eng. J. 203 (2012) 294-300.

[54] A. Ghauch, A.M. Tuqan, Oxidation of bisoprolol in heated persulfate/ $\mathrm{H}_{2} \mathrm{O}$ systems: Kinetics and products,

Chem. Eng. J. 183 (2012) 162-171.

[55] A. Ghauch, A.M. Tuqan, N. Kibbi, Ibuprofen removal by heated persulfate in aqueous solution: A kinetics study, Chem. Eng. J. 197 (2012) 483-492.

[56] A. Ghauch, A.M. Tuqan, N. Kibbi, Naproxen abatement by thermally activated persulfate in aqueous systems, Chem. Eng. J. 279 (2015) 861-873.

[57] R.P. Schwarzenbach, P.M. Gschwend, D.M. Imboden, Environmental Organic Chemistry, Wiley-Interscience, 2002.

[58] K. Yu, S. Yang, C. Liu, H. Chen, H. Li, C. Sun, S.A. Boyd, Degradation of organic dyes via bismuth silver oxide initiated direct oxidation coupled with sodium bismuthate based visible light photocatalysis, Environ. Sci. Technol. 46 (2012) 7318-7326.

[59] Y. Ji, C. Dong, D. Kong, J. Lu, New insights into atrazine degradation by cobalt catalyzed peroxymonosulfate oxidation: kinetics, reaction products and transformation mechanisms, J. Hazard. Mater. 285 (2015) 491-500.

[60] A. Ghauch, A.M. Tuqan, N. Kibbi, S. Geryes, Methylene blue discoloration by heated persulfate in aqueous solution, Chem. Eng. J. 213 (2012) 259-271.

[61] D.B. Luiz, A.K. Genena, E. Virmond, H.J. Jose, R. Moreira, W. Gebhardt, H.F. Schroder, Identification of degradation products of erythromycin arising from ozone and advanced oxidation process treatment, Water Environ. Res. 82 (2010) 797-805.

[62] R.O.C. Norman, P.M. Storey, P.R. West, Electron spin resonance studies. Part XXV. Reactions of sulphate 
radical anion with organic compounds, J. Chem. Soc. B 108 (1970) 1087-1095.

[63] T. Hasan, M. Allen, B.S. Cooperman, Anhydrotetracycline is a major product of tetracycline photolysis, J. Org.

Chem. 50 (1985) 1755-1757.

[64] K.A. Rickman, S. P. Mezyk, Kinetics and mechanism of sulfate radical oxidation of $\beta$-lactam antibiotics in water, Chemosphere 81 (2010) 359-365.

[65] H.F. Dos Santos, W.B. de Almeida, M.C. Zerner, Conformational analysis of the anhydrotetracycline molecule: a toxic decomposition product of tetracycline, J. Pharm. Sci. 87 (1998) 190-195. 
Table 1. Measured apparent activation energy $\left(E_{\mathrm{a}}\right)$ for thermo-activated persulfate oxidation of tetracycline and other organic compounds reported previously.

\begin{tabular}{llc}
\hline Compound & Apparent activation energy $\left(E_{\mathrm{a}}, \mathrm{kJ} \mathrm{mol}^{-1}\right)^{\mathrm{a}}$ & Reference \\
\hline Tetracycline & $70.48 \pm 1.13$ & This study \\
Sulfamethoxazole & 119.6 & {$[49]$} \\
Trimethoprim & 177.8 & {$[50]$} \\
Trichloroethene & $108 \pm 3$ & {$[51]$} \\
Atrazine & 141 & {$[52]$} \\
Diuron & $155.03 \pm 26.4$ & {$[53]$} \\
Bisoprolol & $119.8 \pm 10.8$ & {$[54]$} \\
Ibuprofen & $168 \pm 9.5$ & {$[55]$} \\
Naproxen & $155.03 \pm 26.4$ & {$[56]$} \\
\hline
\end{tabular}

\footnotetext{
${ }^{\mathrm{a}}$ Apparent activation energy $\left(E_{\mathrm{a}}\right)$ was calculated by Arrhenius equation.
} 


\section{Figure Captions}

Fig. 1. Molecular structures of tetracycline (TTC), oxytetracycline (OTC), and chlorotetracycline (CTC). For TTC, $\mathrm{p} K_{\mathrm{a}}$ is 3.3, 7.7 and 9.7, corresponding to the tricarbonylamide, dimethyl amino and phenolic-diketone group [7,8], respectively.

Fig. 2. (A) Effects of temperature on TTC degradation by thermo-activated PS oxidation. Experimental conditions: $[\mathrm{TTC}]=30 \mu \mathrm{M},[\mathrm{PS}]=2 \mathrm{mM}$, Temperature $=40-70{ }^{\circ} \mathrm{C}, \mathrm{pH}=7.0$. (B) The temperature dependency of $k_{\text {obs }}$ evaluated by Arrhenius equation. Error bars represent $95 \%$ confidence intervals of replicates $(n=2)$.

Fig. 3. Effects of solution $\mathrm{pH}$ on TTC degradation by thermos-activated PS oxidation. Experimental conditions: $[\mathrm{TTC}]=30 \mu \mathrm{M},[\mathrm{PS}]=2 \mathrm{mM}$, Temperature $=50{ }^{\circ} \mathrm{C}, \mathrm{pH}=4.0-9.0$. Error bars represent 95\% confidence intervals of replicates $(n=2)$.

Fig. 4. Proposed products of TTC formed in thermo-activated persulfate oxidation process.

Fig. 5. (A) Sulfate radical attacks the dimethylamino moiety of tetracycline molecular structure (A ring), leading to the formation of 4-demethyltetracycline via $N$-dealkylation mechanism, and (B) sulfate radical attacks the phenolic moiety of tetracycline molecular structure (D ring), leading to the formation of quinoid-type compound.

Fig. 6. Time-dependent evolution of products $\mathrm{m} / \mathrm{z} 417,427$ and 459 during tetracycline degradation by thermo-activated persulfate oxidation process. Reaction conditions: $[\mathrm{TTC}]=30$ $\mu \mathrm{M},[\mathrm{PS}]=2 \mathrm{mM}$, Temperature $=50{ }^{\circ} \mathrm{C}, \mathrm{pH}=7.0$. Note that, the abundance of $\mathrm{m} / \mathrm{z} 459$ was minified 10-fold in the figure for visual purpose.

Fig. 7. Comparison of the degradation of TTC with OTC and CTC. Reaction conditions: $[\mathrm{TCs}]=$ $30 \mu \mathrm{M},[\mathrm{PS}]=2 \mathrm{mM}$, Temperature $=50{ }^{\circ} \mathrm{C}, \mathrm{pH}=7.0$. Error bars represent $95 \%$ confidence intervals of replicates $(n=2)$.

Fig. 8. Thermo-activated PS oxidation of TTC in Milli-Q water and artificial surface water (ASW). Reaction conditions: $[\mathrm{TTC}]=30 \mu \mathrm{M},[\mathrm{PS}]=2 \mathrm{mM}$, Temperature $=50^{\circ} \mathrm{C}, \mathrm{pH}=7.0$. Error bars 
represent $95 \%$ confidence intervals of replicates $(n=2)$. 
Figure 1

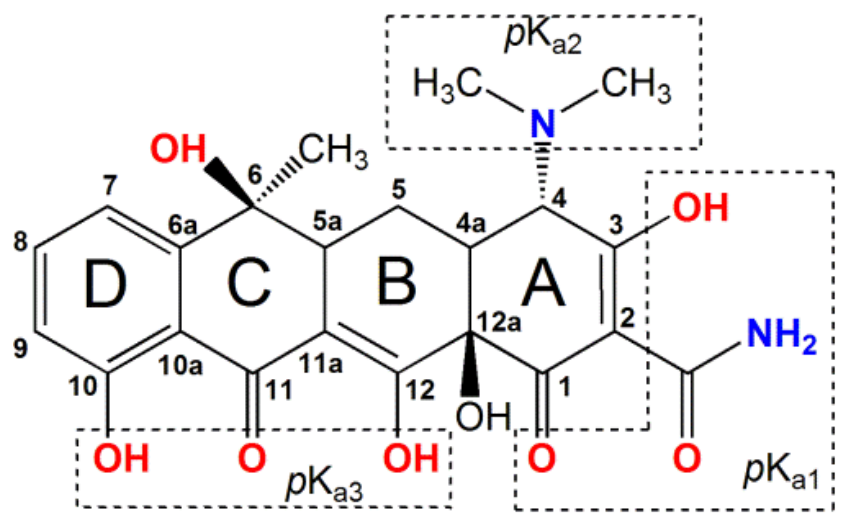

Tetracycline (TTC)
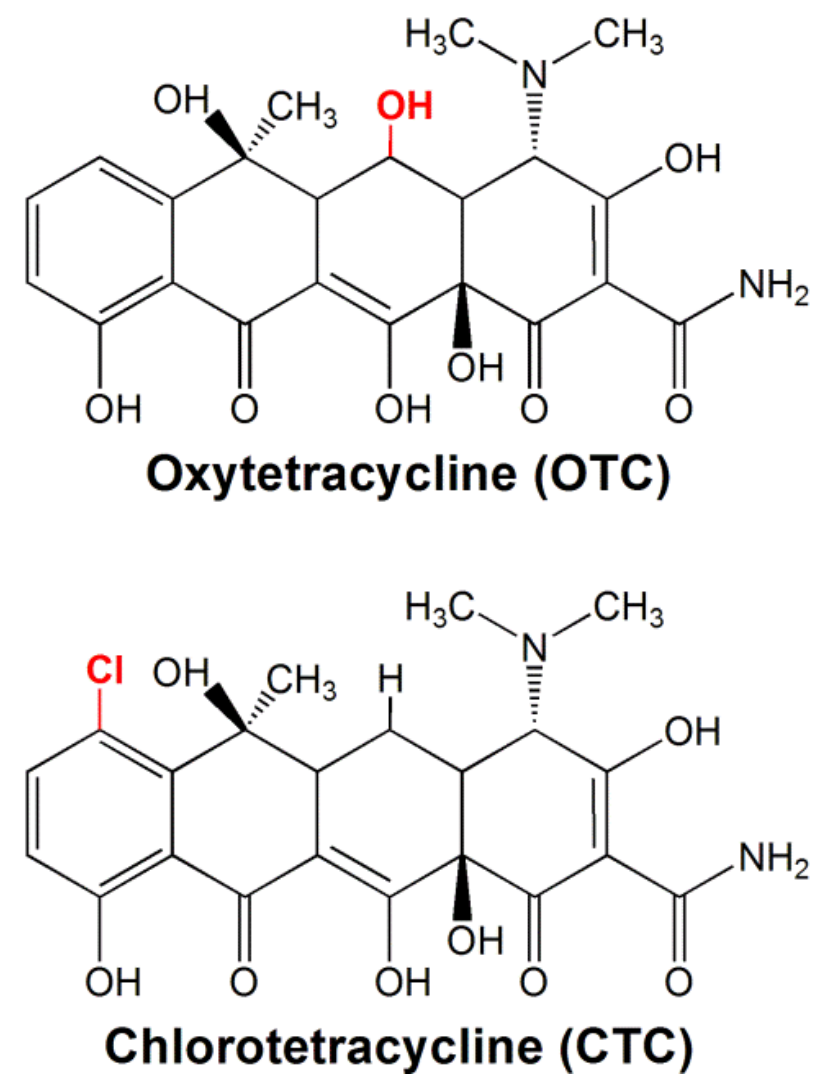
Figure 2
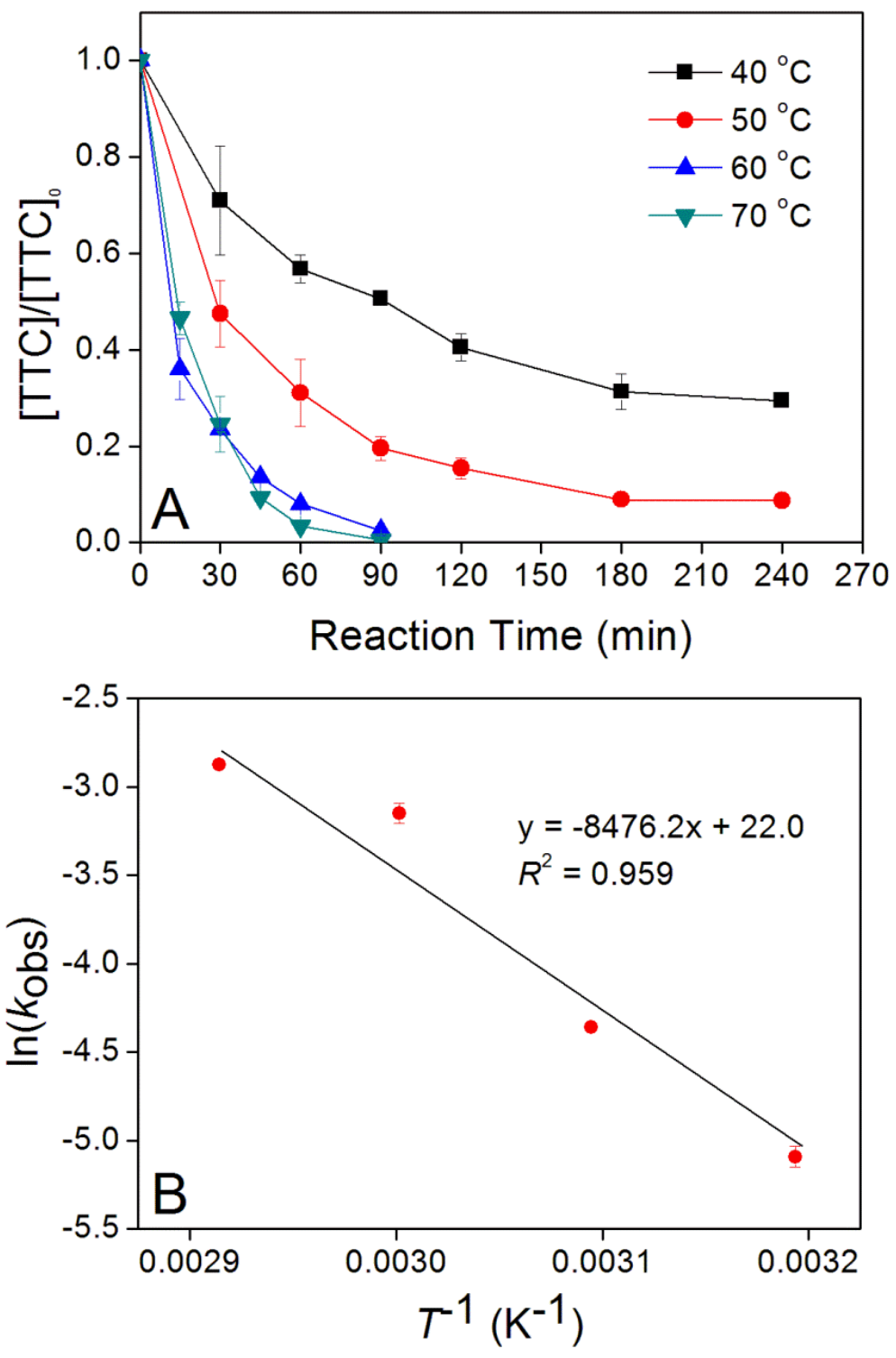
Figure 3

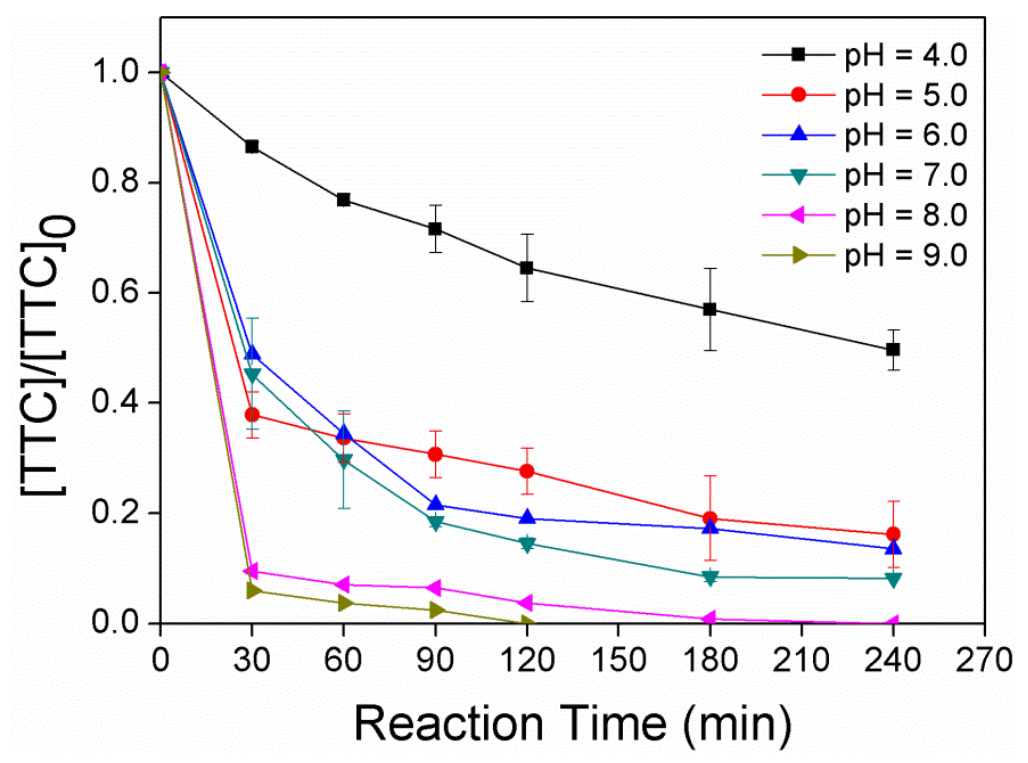


Figure 4<smiles>CN[C@H]1C(O)=C(C(N)=O)C(=O)[C@@]2(O)C(O)=C3C(=O)c4c(O)cccc4[C@@](C)(O)C3CC12</smiles>
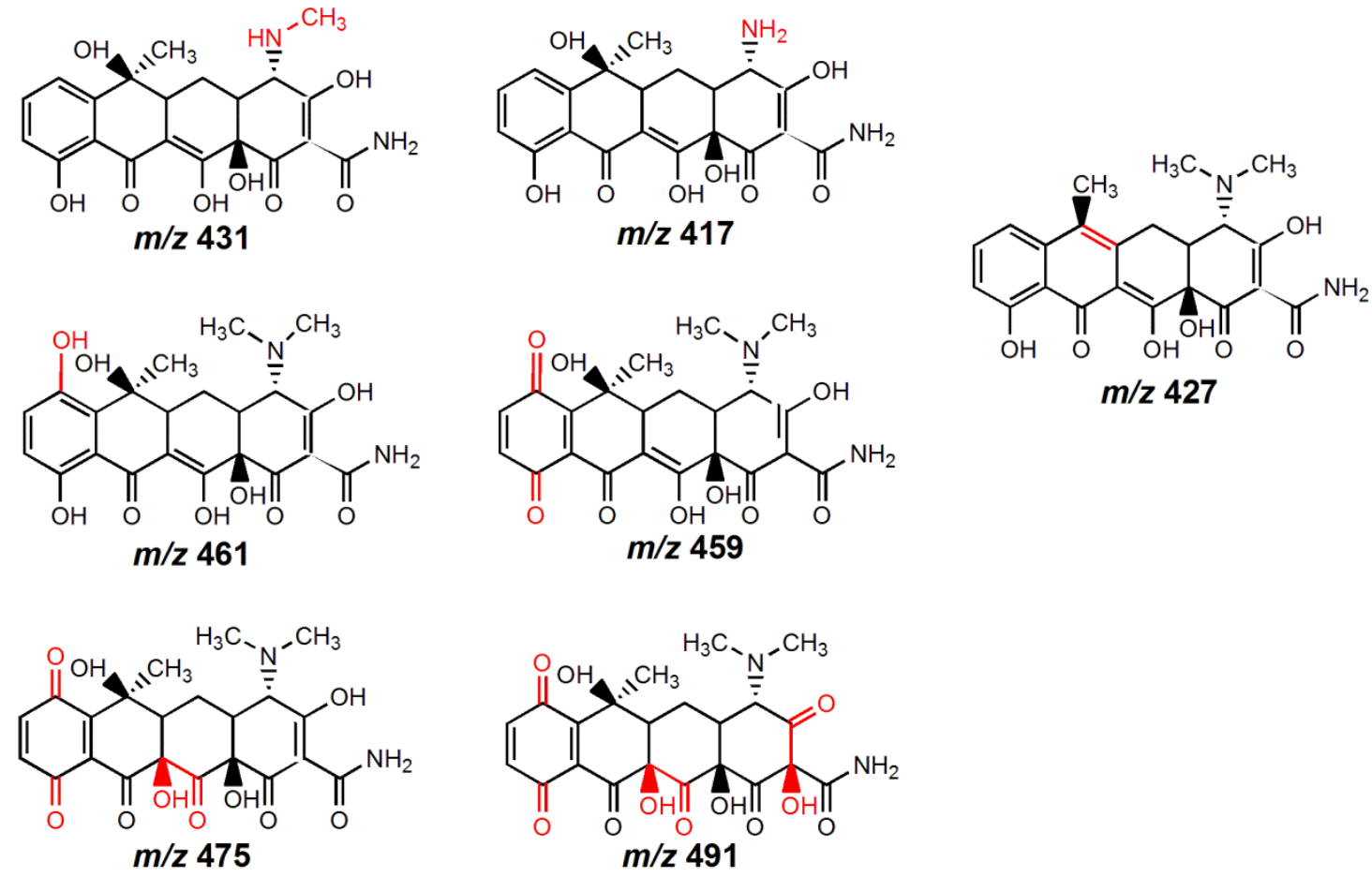

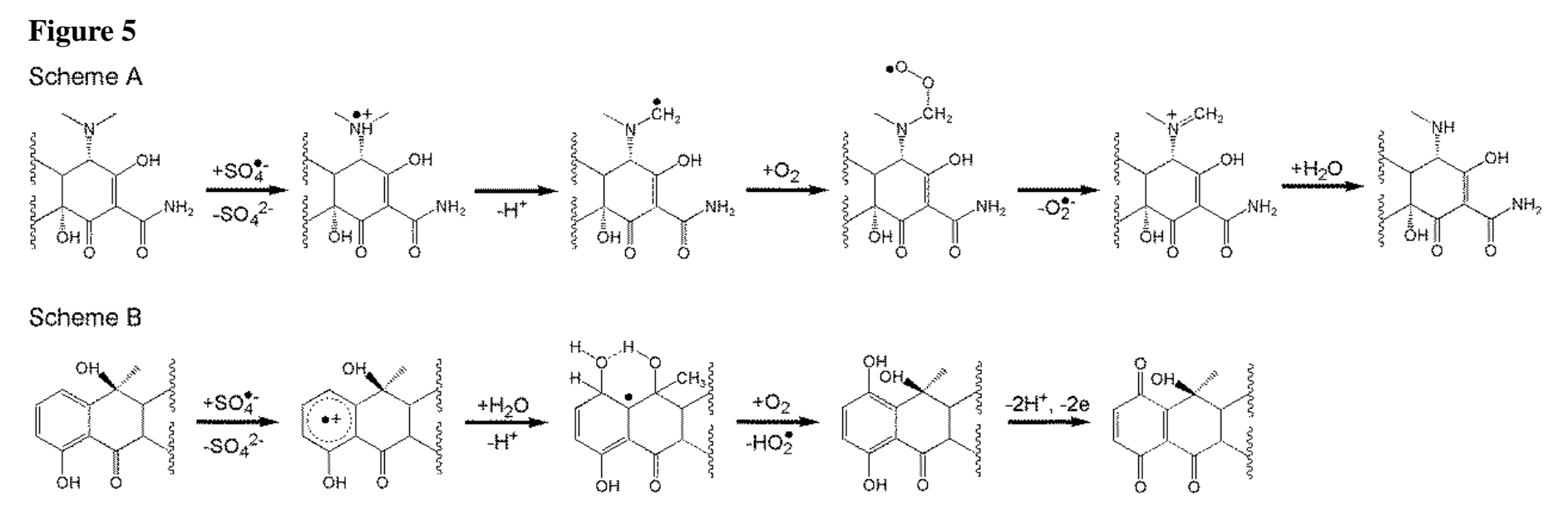
Figure 6

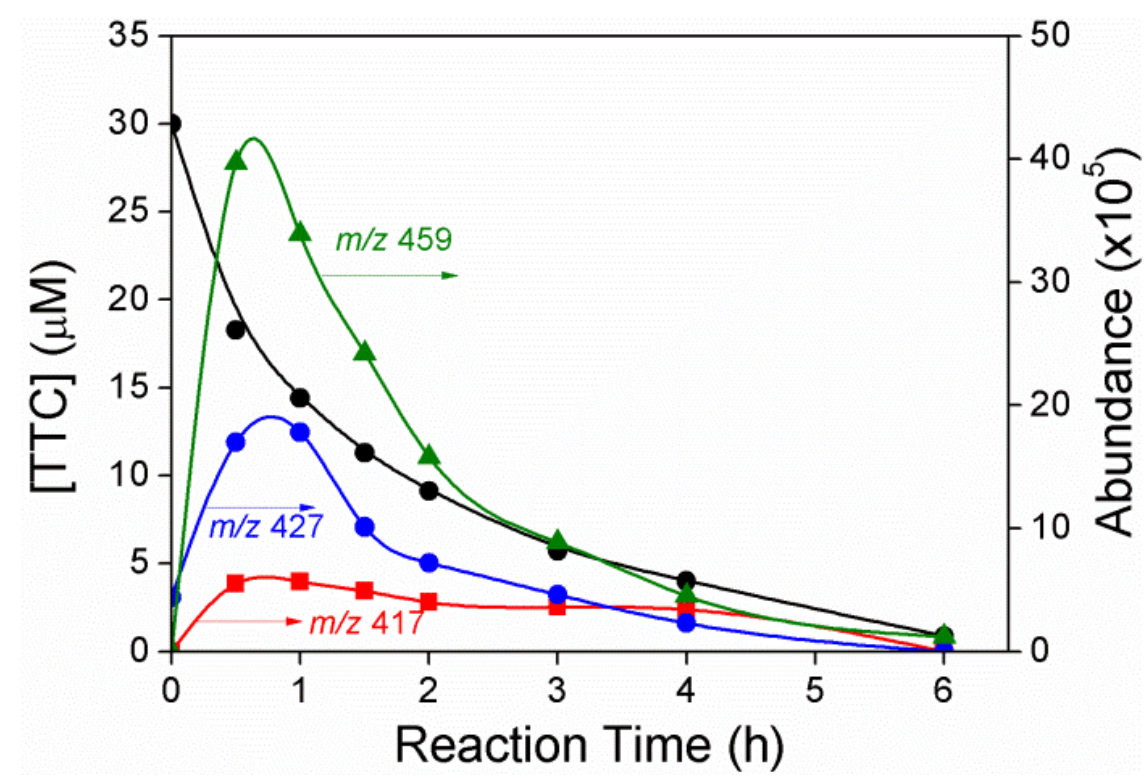


Figure 7

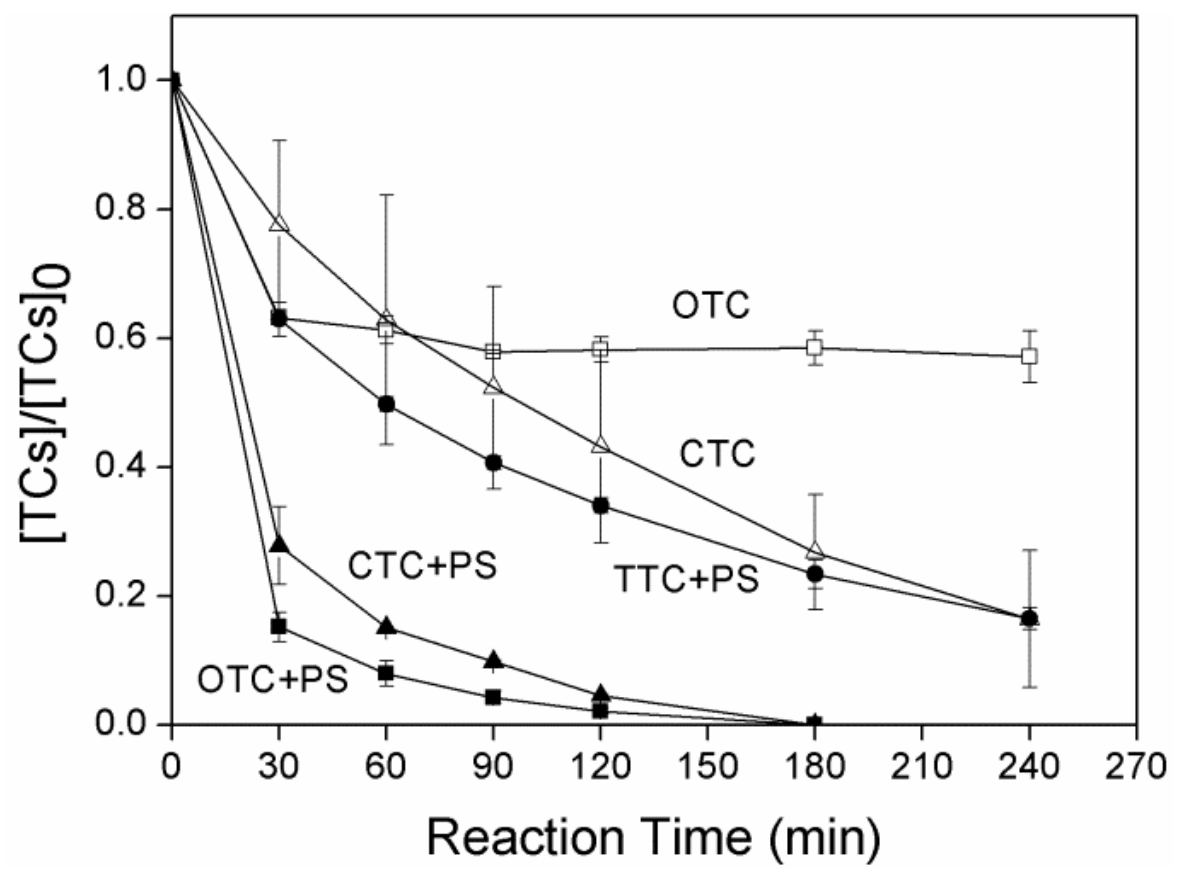


Figure 8

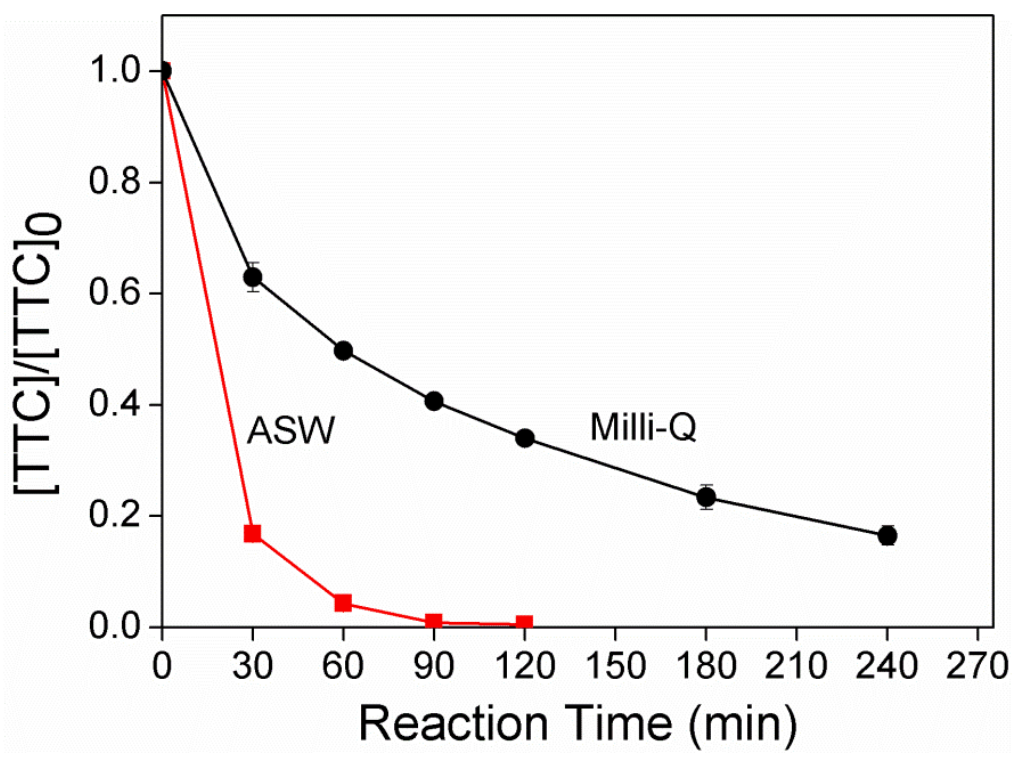




\section{Graphic Abstract}

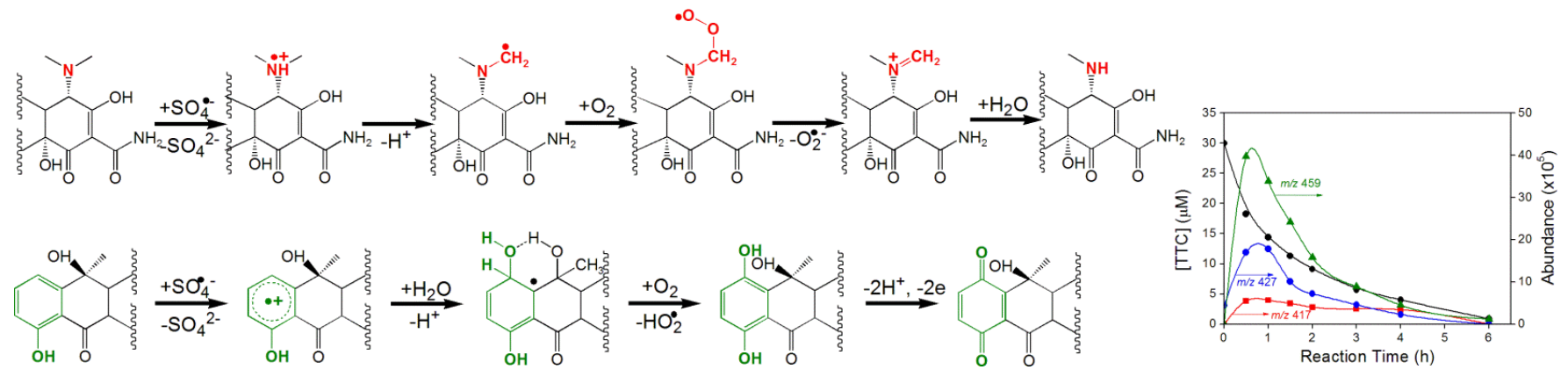

